\title{
The effect of the Saharan climate on the indoor environment of a station of electric energy transformation MV / LV
}

\author{
Amina Hammadou ${ }^{1}$, Abdelkrim Missoum ${ }^{1}$, Elmir Mohamed $^{1}$ Belkacem Draoui $^{1}$ \\ ${ }^{1}$ Laboratory of Energetic in Arid Zone ENERGARID, Mohamed Tahri University Bechar, Algeria
}

\begin{abstract}
The proposed work studies numerically the mixed convection heat transfer in a station electric transformer MV / LV for the public distribution of a neighborhood located in the town of Bechar (Sahara region) in the south-west Algeria. Taking into account the climatic conditions measured during the summer period [1], introduced as boundary conditions using the Fluent CFD based on the finite volume method. In order to get results presented in form the isothermal and the stream function and the profile of the evolution of the temperature and velocity components of the air inside the station. The objective of this study is to analyze the results of the distribution of temperature, aeration of the position and the flow of air to the interior of the station. The influence of the number and location of openings in the station is studied.
\end{abstract}

\section{Introduction}

Algeria is a vast country it is between $18^{\circ}$ and $38^{\circ}$ north latitude and between $9^{\circ}$ west longitude and $12^{\circ}$ east longitude (the International meridian Greenwich $(0$ ${ }^{\circ}$ ) passing near the town of Mostaganem).

Bechar is located in southwest from ALGERIA: latitude : $31^{\circ} 37$ 'N 31.6167 and longitude $2^{\circ} 14^{\prime} \mathrm{W}$ 2.23333 ; it is characterized by a continental climate desert type, with rainfall of about $40 \mathrm{~mm} \mathrm{/} \mathrm{year.}$ Sandstorms are very common, and the average temperature is $35^{\circ} \mathrm{C}\left(+45^{\circ} \mathrm{C}\right.$ in summer and $-5^{\circ} \mathrm{C}$ in winter).

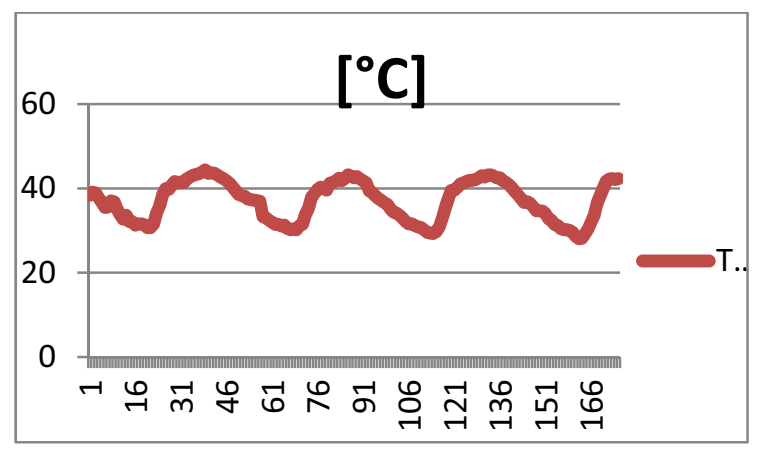

Fig. 1. Outside temperature

The Bechar region therefore has a hot and arid climate. It is then placed in the zone D1 (see figure I.2)

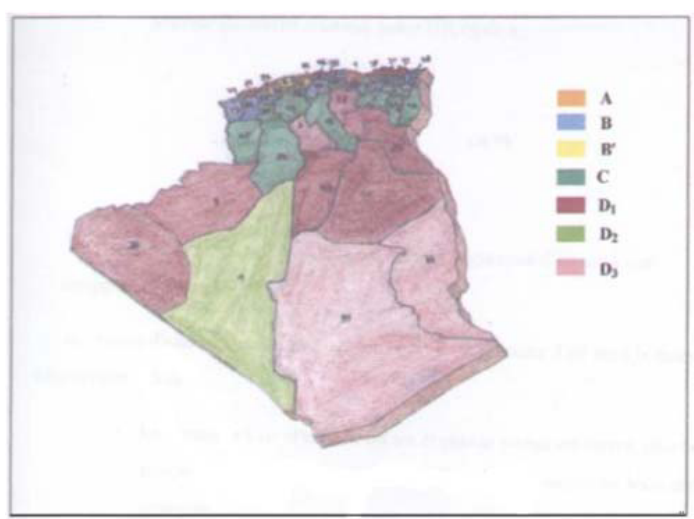

Fig. 2. Climate zones in Algeria

The study is a numerical modeling of heat transfer by mixed convection of transformer station of the electric energy; taking into account the climatic conditions of the region of Bechar.

Mixed convection in rectangular spaces is a very important subject of investigation for its presence in various industrial applications such as : the cooling of electronic components, heat losses in solar collectors and ventilation of rooms and buildings. The laminar flow of forced or natural convection has limited value because the number of Reynolds or Grashof / square Rayleigh must not exceed a certain threshold [2-3].

The mixed convection heat transfer, is of considerable interest for technological applications such as chemical deposition of thin layers, cooling of electronic components [4-10]

A large number of numerical and experimental studies [11-16] relate to heated or isothermal tubes mixed convection. Most of these studies considers the bi-dimensional case with vertical tubes. They studied the effect of dimensionless numbers on the flow behavior in mixed convection. 
The effect of the tilt was considered by [17] and [18] in 3D which assume that the flow has a predominant direction in order to simplify the Navier Stokes equation .

The ventilation of rooms habitat types for buildings is studied by [19] due to the significant increase in temperature in summer in Saharan zones and because of the bad mastery of ventilation in the cavity where there is the electrical transformers there will have nefarious consequences of the quality of indoor air, built conservation and energy consumption. In order to treat this problem, we examine in this work numerically the various positions of the openings in the station and their influence on the inside heat transfer.

\section{Configuration studied}

The configuration studied is shown in Figure 1. This is an electric power processing station for the public distribution of length $\mathrm{L}=3.4 \mathrm{~m}$ and height $\mathrm{H}=2.8 \mathrm{~m}$, equipped with two openings same heights $\mathrm{h} 1=\mathrm{h} 2=$ $0.44 \mathrm{~m}$. One is located at the bottom for the admission of air and the other at the top for the hot air outlet. The wall near the transformer is at a warm temperature Tc and the other wall kept at a cold temperature $\mathrm{Tf}$, too, the floor and the ceiling are supposed Job thermally insulated. The station contains a transformer dimension $\mathrm{e} 1=1.7 \mathrm{~m}, \mathrm{e} 2=1.85 \mathrm{~m}$. The boundary conditions of the station studied are taken from the climatic data of the region of Bechar.

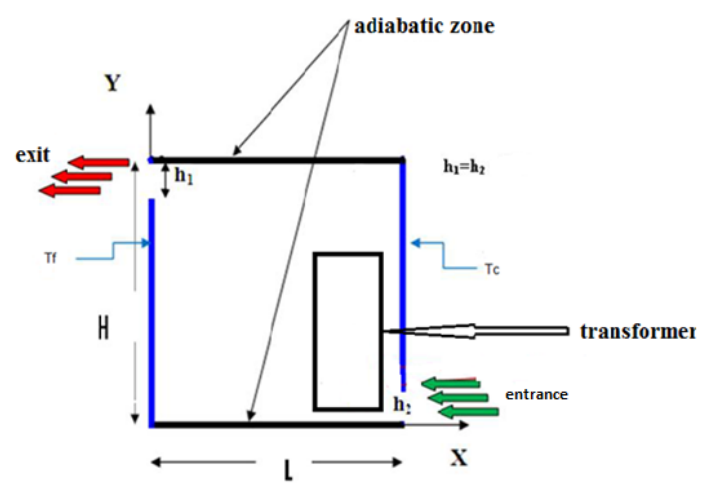

Fig. 3. Geometric Configuration

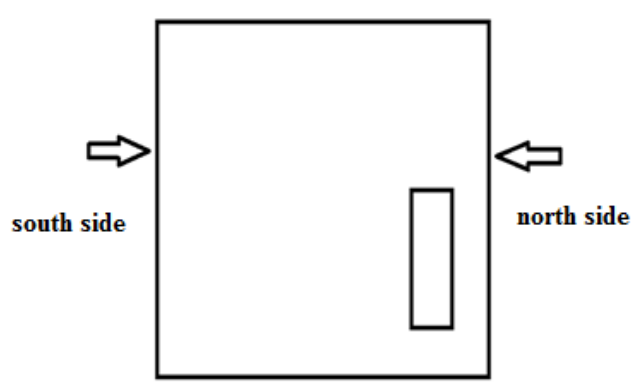

Fig. 4. Sides of the station
To simplify the problem, assume that:

- The fluid is Newtonian and incompressible.

- Heat transfer by radiation is negligible.

- The heat dissipation by viscous friction is neglected.

- The Boussinesq approximation is considered.

- The flow is bidimensional.

\section{Mathematical model}

The system of equations governing the model is written in the following dimensionless form:

a.mass conservation equation (continuity) :

$$
\frac{\partial u}{\partial x}+\frac{\partial v}{\partial y}=0
$$

a. Equations of conservation of momentum :

$$
\begin{aligned}
& \left(\frac{\partial u}{\partial t}+u \frac{\partial u}{\partial x}+v \frac{\partial u}{\partial y}\right)=-\frac{\partial P}{\partial x}+\frac{1}{\operatorname{Re}}\left(\frac{\partial^{2} u}{\partial x^{2}}+\frac{\partial^{2} u}{\partial y^{2}}\right) \\
& \left(\frac{\partial v}{\partial t}+u \frac{\partial v}{\partial x}+v \frac{\partial v}{\partial y}\right)=-\frac{\partial P}{\partial y}+\frac{1}{\operatorname{Re}}\left(\frac{\partial^{2} v}{\partial x^{2}}+\frac{\partial^{2} v}{\partial y^{2}}\right)+\frac{G r}{\operatorname{Re}^{2}} T
\end{aligned}
$$

\section{b. Energy conservation equation:}

$$
\frac{\partial T}{\partial t}+u \frac{\partial T}{\partial x}+v \frac{\partial T}{\partial y}=\frac{1}{\operatorname{Re} \operatorname{Pr}}\left(\frac{\partial^{2} T}{\partial x^{2}}+\frac{\partial^{2} T}{\partial y^{2}}\right)
$$

The initial and boundary conditions:

The previous system of equations must be solved under certain specified conditions

At the entrance :

$\mathrm{U}=\mathrm{V}_{\text {max }} ; \mathrm{V}=0 ; \mathrm{T}=\mathrm{T}_{\mathrm{f}}$

At the exit:

Outflow (all gradients are taxed except zero pressure)

Hot walls:

$$
\mathrm{U}=\mathrm{V}=0 ; \mathrm{T}=\mathrm{T}_{\mathrm{C}}
$$

Vertical walls:

$\mathrm{U}=\mathrm{V}=0 ; \mathrm{T}=\mathrm{T}_{\mathrm{f}}$

Horizontal walls (adiabatic) :

$$
u=v=\frac{\partial T}{\partial x}=0
$$

The numerical procedure used in this work is that of finite volume. It involves the integration of differential equations of mathematical model on finite control volumes for the corresponding algebraic equations. The SIMPLE algorithm was chosen for the coupling speed pressure in the Navier Stokes equations on a staggered grid. Convective terms in all equations are evaluated using the scheme apwindler order. In order to follow any changes in hydrodynamic and thermal fields, we used a uniform mesh. 


\section{Results and discussion}

\section{A) Without insulation}

\section{1) Isotherms and streamlines:}

The isotherms are shown in Figure (5) by varying the number and location of the openings of the station for the fixed climatic conditions; which shows that the temperature exceeds $65^{\circ} \mathrm{C}$ on the transformer and $55^{\circ}$ $\mathrm{C}$ on the sunny sides with an external temperature equal to $45^{\circ} \mathrm{C}$. As it's remarked, the addition of openings reduces slightly the maximum temperature.

The figure (6) shows the streamlines for the same cases; we see that the flow is well distributed around the transformer. We observe the appearance of a vortex which is on the left of the heating element caused by natural convection in the station, therefore its size is considerably weakened by adding openings.

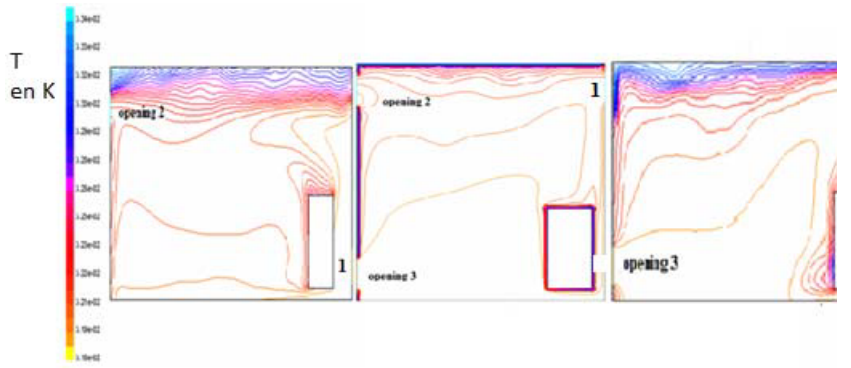

Fig. 5 : Isotherms in the station

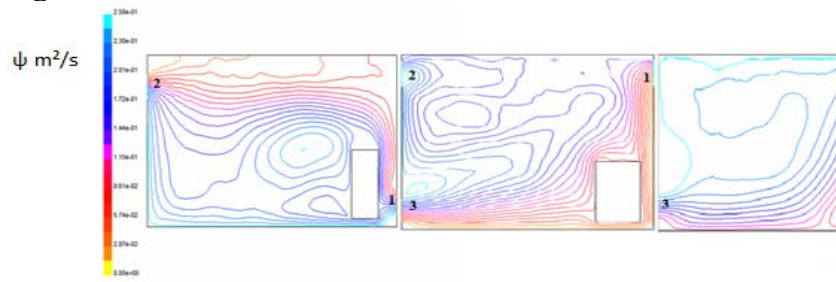

Fig. 6 . Streamlines in the station

The figure (7) show the air circulation in the station.Fresh air enters through the openings at the bottomit it flow over the wall of the transformer, it is heated and by natural convection it heads upwards to come out. In all cases, the top of the transformer is a recirculation zone which is not well refreshed.

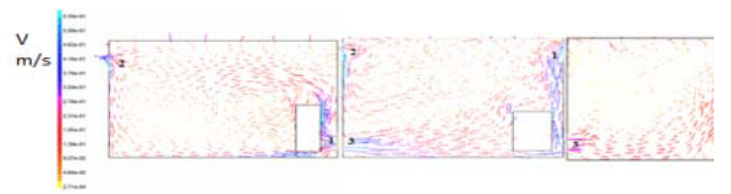

Fig. 7 : Air circulation in the station

\section{B)with insulation}

We tried to insulate the system by a screen in cases of 2 and 4 openings.

\section{1)Isotherms and streamlines :}

By comparing the two cases, it is found that the removal of the solar gain through the insulation lowers the temperature.

The simulation for the previous existing stations fitted with double screen (insulation) on the sunny sides reduces the flow absorbed dramatically. It can be estimated with a dual screen, the temperature applied on protected sides is the same as the temperature of the atmosphere of the time $\left(45^{\circ} \mathrm{C}\right)$. The heating of the transformer is caused by its own power generation.

The greatest value in the station is located on the main of the heat generator transformer. The average temperature of the air inside the station is of the order of $45^{\circ} \mathrm{C}$ to an external temperature of $40^{\circ} \mathrm{C}$ and generally of the order of $5^{\circ} \mathrm{C}$ higher than the external temperature.

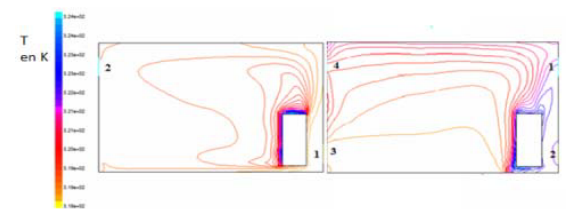

Fig. 8 : Isotherms in the station (with insulation)

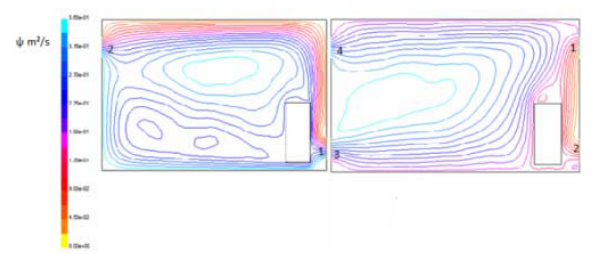

Fig. 9 : Streamlines in the station (with insulation)

The figure (10) shows that the case where there are four opening the air circulation around the transformer is more regular and causes more uniform cooling than in cases where there are only two or three.
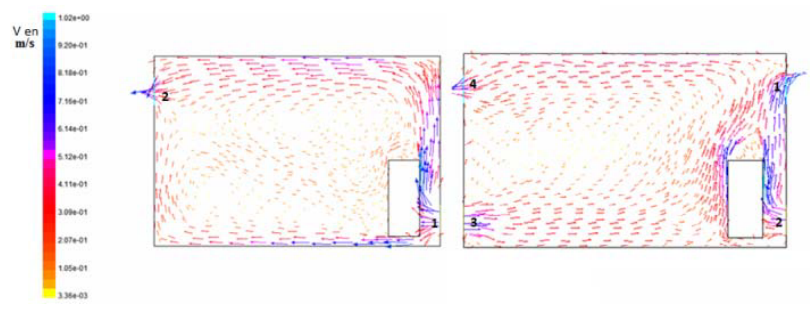

Fig. 10 : Air circulation in the station (with insulation)

\section{C)Temperatures and velocity Profiles:}

Figure (11) illustrates the evolution of the temperature on the line $\mathrm{Y}=2 \mathrm{~m}$ in case of two and three openings; the temperature distribution according to the flow of fluid which it is noted that the temperature does not exceed the ambient $\left(\mathrm{Ta}=45^{\circ} \mathrm{C}\right)$ throughout the area of the transformer in parallel. In the case of low temperatures, we see an increase in temperature up to $\mathrm{Tc}=55^{\circ} \mathrm{C}$ just after the position $\mathrm{X}=2.3 \mathrm{~m}$ to stabilize until almost hot wall characterizes the heat 
transfer is dominated by conduction. As against where was added an additional opening the temperature area of renewal increases rapidly from the position $\mathrm{X}=3.3$ $\mathrm{m}$ to reach the hottest value which is why the transfer by convection is predominant.throughout the area of the transformer in parallel. In the case of low temperatures, we see an increase in temperature up to $\mathrm{Tc}=55^{\circ} \mathrm{C}$ just after the position $\mathrm{X}=2.3 \mathrm{~m}$ to stabilize until almost hot wall characterizes the heat transfer is dominated by conduction. As against where was added an additional opening the temperature area of renewal increases rapidly from the position $\mathrm{X}=3.3$ $\mathrm{m}$ to reach the hottest value which is why the transfer by convection is predominant.

The profile of the average vertical velocity at a height of $\mathrm{Y}=2 \mathrm{~m}$ in both cases is shown in Figure (12). A sharp decrease of the vertical velocity is noted

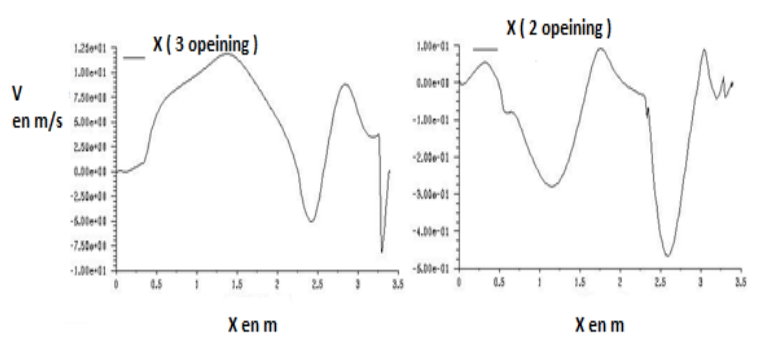

Fig. 12 : the temperature profile at $2 \mathrm{~m}$ height along the station

\section{Conclusion}

The maximum temperature reached $55^{\circ} \mathrm{C}$ greater than ambient temperature that is to say that the heat flow from the transformer increases the heating of indoor air.

The multiplication of openings and regular cleaning are the first inexpensive solution to reduce the heat load on the stations.

A more interesting solution is to have on the sunny faces, in addition to openings; Double lightweight material screen that has the effect of removing the solar heat flux incident on these surfaces and is the main cause of the warming of the stations.

\section{Nomenclatures}

g Gravitational acceleration [m/s2]

H Height of the cavity [m]

L The cavity length [m]

$\mathrm{h} 1$ evacuation length $[\mathrm{m}]$

h2 Length of entered [m]

e1 The thickness of the heating element [m]

e2 The height of the heating element [m] to achieve minimum values about $\mathrm{X}=0.5$. However the highest rate values are met in the range $0.8<\mathrm{X}<$ 2.5 (i.e. of near heating corpd). These values indicate where the fluid particles follow the streamlines in ascending and descending movement.

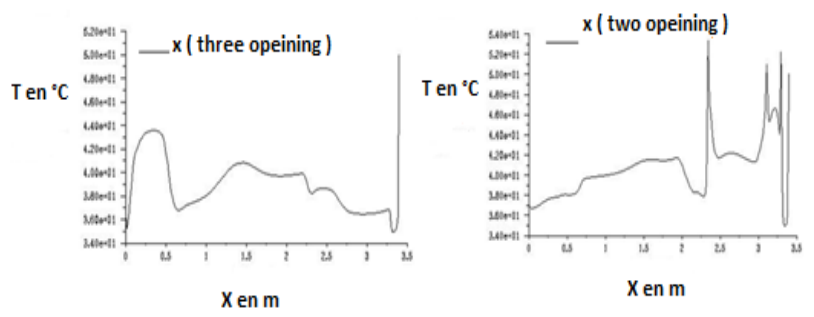

Fig. 11 : the temperature profile at $2 \mathrm{~m}$ height along the station

$\mathrm{U}, \mathrm{V}$ velocity vector Components $[\mathrm{m} / \mathrm{s}]$

\section{Greek symbols}

\author{
$\lambda$ Thermal conductivity $[\mathrm{W} / \mathrm{mK}]$ \\ $\boldsymbol{\mu}$ Dynamic viscosity [Kg M-1 / s-1] \\ v Kinematic viscosity $[\mathrm{m} 2 / \mathrm{s}]$

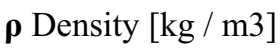

$\Delta$ Temperature difference $[\mathrm{K}]$

\section{References}

[1] climatic data of the region of Bechar. weather station of Bechar university

[2] Sefcik, D. M., Webb, B. W., Heaton, H. S., “ Analysis of Natural

Convection in Vertically-Vented Enclosures, " Int. J. Heat Mass

Transfer 34: 3037-3046,1991.

[3] Yu, E., Joshi, Y., “ A Numerical Study of ThreeDimensi-onal Laminar

Natural Convection in a Vented,Enclosure, 'Int. J. Heat and Fluid Flow

18: 600-612. 1997.

[4] A. Zebib, Y.K. Wo, “A two-dimensional conjugate heat transfer model

for forced air cooling of an electronic device, "Transactions of ASME J.

Electronic Packaging 111 (1989) 41-45,1989.

[5] K. Hijikata, W. Nakayama, T. Nagasaki, R. Kurazume, K. Fushinobu, “

A study on heat transfer from small heating element in an integrated

circuit chip," Proc. of the 3rd ASME/JSME Thermal Engineering Joint

Conf. 4, , pp. 93-98,1991.

[6] T. Nagasaki, K. Hijikata, K. Fishinobu, P.E. Phelan, "Numerical simulation of the conjugate direct cooling of a micro heat generating 
element, " Proc. ASME/JSME Conf. on Electronic Packaging 1, pp.

217-223, 1992.

[7] K. Fushinobu, P.E. Phelan, T. Nagasaki, K. Hijikata, M.I.Flik, " Periodic

steady-state thermal analysis of a high-Tc superconducting

microbolometer, " Trans. ASME J. Heat Transfer. 116 (1994) 278-

275,1994 .

[8] K. Fushinobu, K. Hijikata, Y. Kurosaki, "Heat transfer regime map for

electronic devices cooling, Int. J. Heat Mass Transfer. 39 (1996) 3139-

$3145,1996$.

[9] B.A. Jubran, S.A. Swiety, M.A. Hamdan., Convective heat transfer and

pressure drop characteristics of various array configurations to simulate

the cooling of electronic modules, 'Int. J. Heat Mass

Transfer. 39 (1996)

3519-3529,1996.

[10] M. Hasnaoui, E. Bilgen, P. Vasseur, "Natural convection above an array

open cavities heated from below, "Numerical Heat Transfer. Part A 18

(1991) 463-482, 1991.

[11] M. Zghal, N. Galanis et C.T. Nguyen, "Developing mixed convection

with aiding buoyancy in vertical tubes: a numerical investigation of

different flow regions, 'Int. J. Therm. Sci., 40, pp 816824, 2001.

[12] T. Maré , I. Voicu et P. Hue, "Visualisation d'un écoulement en

convection mixte pour tube isotherme incliné, " Cit 2628 Mai, Québec,

40-07, 2003.

[13] A. Behzadmehr, N. Galanis et A. Laneville, “ low Reynods Nguyen,

Developing mixed convection with aiding buoyancy in vertical tubes: a

numerical investigation of different flow regions, "Int. J. Heat. Mass.
Transfer, 46, pp 4823-4833, 2003.

[14] J. Orfi, N. Galanis , “ Developing Laminar Mixed Convection with Heat

and Mass Transfer in horizontal and vertical tubes," Int. J. Thermt.Sci.,

41, pp 319-331, 2002.

[15] D. D. Joye, " Pressure drop correlation for laminar, mixed convection,

aiding flow heat transfer in a vertical tube, ” Int. J. Heat Fluid Flow, 24, pp 260-266, 2003.

[16] C. T. Nguyen, S. B. Maiyer, M. Landry, N. Galanis et G. " Roy

Numerical investigation of flow reversal and instability in mixed laminar

vertical tube flow, " Int. J. Therm. Sci., 43, pp 797-808, 2004.

[17] A. Barletta et E. Zanchini, "Time -periodic laminar mixed convection in

a inclined channel, " Int. J. Heat. Mass. Transfer, 46, pp 551-563, 2003.

[18] J. Orfi, N. Galanis et C. T. Nguyen , "Développement simultané

hydrodynamique et thermique d'un écoulement laminaire dans un tube

incliné en régime de convection mixte, " Rev. Gén. Therm., 36, pp 83-

92, 1997.

[19] E. Benachour "simulation numérique de la convection naturelle et mixte

dans une cavité carée (type habitat) avec la présence d'un élément de

climatisation, " mémoire de magister, Université de Béchar, Algerie, 07 mars 2010.

[20] Mr. Modest "Radiative heat transfer", The McGraw-Hill Companies ed. (2002)

[21] R. Siegel and J. R. Howell, "Thermal radiation heat transfer", Taylor and Francis ed. (1992).

[22] E. Benachour, Numerical Simulation of the Mixed convection of a room (habitat type) with the presence of a heating element, J S R No. 0 Vol. 1 (2010) 